\title{
Robot-assisted thoracolaparoscopic esophagolymphadenectomy for esophageal cancer
}

\author{
J. Boone · I. H. M. Borel Rinkes · R. van Hillegersberg
}

Received: 31 July 2007/ Accepted: 29 August 2007/Published online: 10 October 2007

(C) Springer Science+Business Media, LLC 2007

With interest we read the article by Kernstine and colleagues, describing their initial experience with totally robot-assisted thoracolaparoscopic esophagolymphadenectomy [1]. Their series consisted of three consecutive groups, each combining the robot-assisted thoracoscopic procedure with either open abdominal surgery, laparoscopy, or robot-assisted laparoscopy. These groups represent the learning curve followed by the authors.

Indeed, we followed a similar strategy with our first 21 cases of robot-assisted thoracolaparoscopic esophagolymph-adenectomy, published in this journal in 2006 [2]. We experienced a steep learning curve and found a reduction of the pulmonary complication rate only after we had introduced the laparoscopic abdominal phase. This is consistent with previous reports of conventional thoracolaparoscopic esophagectomy [3].

Before introducing the procedure in our clinic, we tested the port position and the position of the robotic system extensively in a cadaveric study and came to a thoracic position similar to that presented by Kernstine et al. [1]. The position of the robotic system in our setup, however, is more dorsocranial [2, 4].

In our experience, the Da Vinci robotic system (Intuitive Surgical, Inc, Sunnyvale, CA, USA) has been very beneficial during the thoracoscopic phase of esophageal resection and lymph node dissection, allowing for a very precise dissection along the vital mediastinal structures. Yet, we have found the robotic system less suitable for the abdominal phase, requiring maneuvers with large amplitude leading to collisions of the robotic arms. Especially

J. Boone $(\varangle)$ - I. H. M. Borel Rinkes · R. van Hillegersberg Department of Surgery, University Medical Center Utrecht, Heidelberglaan 100, 3584 CX Utrecht, The Netherlands e-mail: jboone2@umcutrecht.nl during the dissection along the greater curvature of the stomach, a large area of various positions must be covered. We therefore perform the abdominal phase by conventional laparoscopy using an ultrasonic dissector device. Selective use of the robot can save operating time. The median operating time for robot-assisted thoracoscopy with conventional laparoscopy is $7.5 \mathrm{~h}$ [2], compared with $11.2 \mathrm{~h}$ in case of the totally robotic procedure [1].

The authors do not describe any benefit from use of the robotic system during the abdominal phase. The median number of lymph nodes dissected in the current series was less than in our series (18 [1] vs 20 [2]), eventhough the authors denominate their procedure a three-field lymph node dissection. A formal cervical lymph node dissection was not performed in this series, so actually a two-field lymphadenectomy was performed [5].

With regard to the azygos vein, we agree with the authors that the trunk of this vein can be preserved during robot-assisted thoracoscopic esophagolymphadenectomy. We have recently shown in a cadaveric study that preservation of the azygos vein during thoracic esophagolymphadenectomy did not substantially affect the extent of mediastinal lymph node harvesting [6].

\section{References}

1. Kernstine KH, DeArmond DT, Shamoun DM, Campos JH (2007) The first series of completely robotic esophagectomies with threefield lymphadenectomy: initial experience. Surg Endosc (Epub ahead of print)

2. van Hillegersberg R, Boone J, Draaisma WA, Broeders IA, Giezeman MJ, Borel Rinkes IHM (2006) First experience with robot-assisted thoracoscopic esophagolymphadenectomy for esophageal cancer. Surg Endosc 20:1435-1439

3. Luketich JD, Alvelo-Rivera M, Buenaventura PO, Christie NA, McCaughan JS, Litle VR, Schauer PR, Close JM, Fernando HC 
(2003) Minimally invasive esophagectomy: outcomes in 222 patients. Ann Surg 238:486-494

4. Boone J, Draaisma WA, Schipper MEI, Broeders IAMJ, Borel Rinkes IHM, van Hillegersberg R (2007) Robot-assisted thoracoscopic esophagectomy for a giant upper esophageal leiomyoma. Dis Esophagus doi: 10.111/j.1442-2050.2007.0070g.X

5. Lerut T, Nafteux P, Moons J, Coosemans W, Decker G, De Leyn P, Van Raemdonck D, Ectors N (2004) Three-field lymphadenec- tomy for carcinoma of the esophagus and gastroesophageal junction in 174 R0 resections: impact on staging, disease-free survival, and outcome: a plea for adaptation of TNM classification in upper-half esophageal carcinoma. Ann Surg 240:962-972

6. Boone J, Schipper MEI, Bleys RLAW, Borel Rinkes IHM, van Hillegersberg R (2007) The effect of azygos vein preservation on mediastinal lymph node harvesting in thoracic esophagolymphadenectomy. Dis Esophagus doi: 10.111/j.1442-2050.2007.00760.x 